\title{
Persistent residential burning-related primary organic particles during wintertime hazes in North China: insights into their aging and optical changes
}

\author{
Lei Liu ${ }^{1}$, Jian Zhang ${ }^{1}$, Yinxiao Zhang ${ }^{1}$, Yuanyuan Wang ${ }^{1}$, Liang Xu ${ }^{1}$, Qi Yuan ${ }^{1}$, Dantong Liu $^{1}$, Yele Sun ${ }^{2}$, \\ Pingqing $\mathrm{Fu}^{3}$, Zongbo Shi ${ }^{4}$, and Weijun $\mathrm{Li}^{1}$ \\ ${ }^{1}$ Department of Atmospheric Sciences, School of Earth Sciences, Zhejiang University, Hangzhou 310027, China \\ ${ }^{2}$ State Key Laboratory of Atmospheric Boundary Layer Physics and Atmospheric Chemistry, \\ Institute of Atmospheric Physics, Chinese Academy of Sciences, Beijing 100029, China \\ ${ }^{3}$ Institute of Surface-Earth System Science, Tianjin University, Tianjin 300072, China \\ ${ }^{4}$ School of Geography, Earth and Environmental Sciences, University of Birmingham, Birmingham, B15 2TT, UK
}

Correspondence: Weijun Li (liweijun@zju.edu.cn)

Received: 29 September 2020 - Discussion started: 15 October 2020

Revised: 1 January 2021 - Accepted: 10 January 2021 - Published: 16 February 2021

\begin{abstract}
Primary organic aerosols (POAs) are a major component of $\mathrm{PM}_{2.5}$ in winter polluted air in the North China Plain (NCP), but our understanding of the atmospheric aging processes of POA particles and the resulting influences on their optical properties is limited. As part of the Atmospheric Pollution and Human Health in a Chinese Megacity (APHH-Beijing) program, we collected airborne particles at an urban site (Beijing) and an upwind rural site (Gucheng, Hebei province) in the NCP during 13-27 November 2016 for microscopic analyses. We confirmed that large numbers of light-absorbing spherical POA (i.e., tarball) and irregular POA particles with high viscosity were emitted from domestic coal and biomass burning at the rural site and were further transported to the urban site during regional wintertime hazes. During the heavily polluted period $\left(\mathrm{PM}_{2.5}\right.$ $>200 \mu \mathrm{g} \mathrm{m}^{-3}$ ), more than $60 \%$ of these burning-related POA particles were thickly coated with secondary inorganic aerosols (named as core-shell POA-SIA particles) through the aging process, suggesting that $\mathrm{POA}$ particles can provide surfaces for the heterogeneous reactions of $\mathrm{SO}_{2}$ and $\mathrm{NO}_{x}$. As a result, during the heavily polluted period, their average particle-to-core diameter ratios at the rural and urban sites increased to 1.60 and 1.67 , respectively. Interestingly, we found that the aging process did not change the morphology and sizes of POA cores, indicating that the burning-related POA particles are quite inert in the atmosphere and can be
\end{abstract}

transported over long distances. Using Mie theory we estimated that the absorption capacity of these POA particles was enhanced by $\sim 1.39$ times in the heavily polluted period at the rural and urban sites due to the "lensing effect" of secondary inorganic coatings. We highlight that the lensing effect on burning-related POA particles should be considered in radiative forcing models and authorities should continue to promote clean energy in rural areas to effectively reduce primary emissions.

\section{Introduction}

Atmospheric aerosol particles can affect regional and global energy budgets by scattering or absorbing solar radiation, modify microphysical properties of clouds by acting as cloud condensation nuclei (CCN), and exert adverse effects on human health such as respiratory and cardiovascular diseases (IPCC, 2013; West et al., 2016). With rapid industrialization and urbanization in the past decades, severe air pollution characterized by high concentrations of fine particulate matter $\left(\mathrm{PM}_{2.5}\right)$ frequently occurs in China, especially the regional hazes in the North China Plain (NCP), which has been the subject of wide concerns of the public, authorities, and scientists (Sun et al., 2016). Many previous studies have shown that synergetic effects from extensive emissions of 
primary particles and gaseous precursors, efficient secondary aerosol formation, regional transport, and unfavorable meteorological conditions are the main factors contributing to haze formation in the NCP (Chang et al., 2018; Liu et al., 2016; Zhong et al., 2019). In particular, long-term measurements have confirmed that wintertime haze episodes in Beijing are commonly initiated by regional transport of air pollutants from the south NCP (e.g., Hebei and Henan provinces) under weak southerly winds and then evolve through massive secondary aerosol formation via heterogeneous reactions (Ma et al., 2017; Sun et al., 2014; Zheng et al., 2015).

During the regional transport and evolution of haze episodes, complex physical and chemical processes in the atmosphere, such as condensation, coagulation, and heterogeneous reactions, could largely alter the morphology, composition, size, and mixing state of individual particles, which is also known as "particle aging" ( $\mathrm{Li}$ et al., 2016a). Particle aging could further influence the optical property, health effects, hygroscopicity, and CCN activity of aerosol particles, although different types of particles might have different impacts (Fan et al., 2020; Li et al., 2016b; Riemer et al., 2019). Up to now, most of the studies conducted in the NCP have mainly applied various online and offline bulk aerosol analytical techniques (e.g., online aerosol mass spectrometry (AMS) and offline ion chromatography (IC)) to explore mass concentrations, possible sources, and formation mechanisms of different aerosol components, such as sulfate, nitrate, and organics (Chen et al., 2020; Cheng et al., 2016; J. Li et al., 2020; Sun et al., 2016; Wang et al., 2020). However, knowledge of the aging process of aerosol particles remains limited. Therefore, to further document the aging processes of different particles in the NCP through microscopic individual particle analysis is of great significance for revealing the particle transformation in the atmosphere and better assessing the climatic effects of aerosols (Du et al., 2019; Li et al., 2016a).

Field observations have shown that carbonaceous aerosols, including organic aerosols (OAs) and black carbon (BC), are the dominant components of $\mathrm{PM}_{2.5}$ during heating seasons in the NCP, which usually account for more than $50 \%$ of the total $\mathrm{PM}_{2.5}$ (Liu et al., 2020; P. Liu et al., 2017; Zhang et al., 2020). Source apportionments reveal that residential coal and biomass burning in rural areas are the major contributors to carbonaceous aerosols during wintertime hazes in the NCP (Li et al., 2017). BC is the major light-absorbing aerosol in the atmosphere and can strongly absorb solar radiation and thus affect the regional and global climate (Bond et al., 2013; D. Liu et al., 2017; Wang et al., 2014). In recent years, several studies have documented well the aging process of BC particles and revealed that secondary inorganic and organic coatings (e.g., sulfate and organics) can significantly enhance the light absorption capacity of the internally mixed BC particles via the "lensing effect" (Chakrabarty and Heinson, 2018; Wang et al., 2017). Recently, light-absorbing organic aerosols, also known as brown carbon $(\mathrm{BrC})$, have been reported to be ubiquitous in the atmosphere in the NCP (Wang et al., 2018; Xie et al., 2019). Many studies have demonstrated that primary OAs (POAs) emitted from residential coal and biomass burning are the major source of $\mathrm{BrC}$, and the chemical composition and optical properties of $\mathrm{BrC}$ in freshly emitted POAs as well as the $\mathrm{BrC}$ in the ambient atmosphere have been analyzed in detail using bulk techniques such as mass spectrometry and UV-visible spectrophotometry (M. Li et al., 2019; X. Li et al., 2020; Song et al., 2018; Sun et al., 2017; Yan et al., 2017). However, only a few studies have characterized microscopic properties such as the morphology and mixing state of fresh burning-related POA particles by transmission electron microscopy (TEM) (L. Liu et al., 2017; Zhang et al., 2018). The abundance and aging process of burning-related POA particles in the atmosphere and the resulting influences on their optical properties remain unknown in the NCP.

This study, as part of the Atmospheric Pollution and Human Health in a Chinese Megacity (APHH-Beijing) program (Shi et al., 2019), aims to explore the atmospheric aging process of POA particles emitted from the residential coal and biomass burning in rural areas following the regional transport and evolution of haze episodes. Individual particle samples were collected in urban Beijing and the surrounding rural regions during the winter campaign and then were analyzed by microscopic methods to obtain the morphology, composition, size, and mixing state of different individual particle types. Besides, bulk analyses of aerosol chemical composition were also conducted to help understand the evolution of haze episodes. We found that large numbers of POA particles were emitted from domestic coal and biomass burning in winter in the NCP. For the first time, we characterized the aging process of such burning-related POA particles based on microscopic analyses, and Mie theory was used to further explore the resulting influences on their optical properties.

\section{Experimental methods}

\subsection{Sampling sites and sample collections}

Field observations were carried out simultaneously at the Beijing (BJ) urban site $\left(39^{\circ} 58^{\prime} 27^{\prime \prime} \mathrm{N}, 116^{\circ} 22^{\prime} 16^{\prime \prime} \mathrm{E}\right)$ and Gucheng (GC) rural site $\left(39^{\circ} 08^{\prime} 58^{\prime \prime} \mathrm{N}, 115^{\circ} 44^{\prime} 00^{\prime \prime} \mathrm{E}\right)$ during 13-27 November 2016. The locations of the two sampling sites in the NCP are displayed in Fig. 1a. The BJ urban site, located on the rooftop of a two-story building ( $8 \mathrm{~m}$ above ground level, a.g.l.) in the Tower Division of the Institute of Atmospheric Physics, Chinese Academy of Sciences, is between the North 3rd Ring Road and North 4th Ring Road and surrounded by commercial area and residential apartments (Fig. 1b). The GC rural site, located on the rooftop of a three-story building (12 m a.g.l.) at the Gucheng Integrated Ecological-Meteorological Observation and Experi- 
mental Station of the Chinese Academy of Meteorological Sciences in Dingxing County, Hebei province, is $120 \mathrm{~km}$ to the southwest of the BJ urban site and surrounded by many villages and farmlands (Fig. 1c). Detailed information about the two sampling sites can be found in the introductory paper of the APHH-Beijing program (Shi et al., 2019). The $24 \mathrm{~h}$ backward trajectories of air masses ending at the height of $100 \mathrm{~m}$ a.g.l. over the BJ urban site (Fig. 1a) were calculated using the NOAA Air Resources Laboratory's HYSPLIT model (Stein et al., 2016).

At the BJ urban site, the species in non-refractory submicron aerosols (NR-PM $)_{1}$ including organic matter $(\mathrm{OM})$, $\mathrm{SO}_{4}^{2-}, \mathrm{NO}_{3}^{-}, \mathrm{NH}_{4}^{+}$, and $\mathrm{Cl}^{-}$were measured by a highresolution aerosol mass spectrometer (HR-AMS; Aerodyne Research, Inc., USA). At the GC rural site, $\mathrm{PM}_{2.5}$ samples were collected twice a day during the daytime (08:00 to 20:00) and nighttime (20:00 to 08:00 the next day) onto $90 \mathrm{~mm}$ diameter quartz filters (Pallflex 7204, Pall Corporation, USA) using a medium-volume sampler (TH-150A, Wuhan Tianhong Instruments Co., Ltd., China) at a flow rate of $100 \mathrm{~L} \mathrm{~min}^{-1}$. Field blank samples were collected for approximately $15 \mathrm{~min}$ without starting the sampler. The filters were prebaked at $450^{\circ} \mathrm{C}$ for $6 \mathrm{~h}$ before sampling to remove any possible contaminants. All the collected samples were sealed individually in aluminum foil bags and stored in a refrigerator at $-20^{\circ} \mathrm{C}$ for further analyses.

Individual particle samples were collected onto copper (Cu) TEM grids coated by formvar and carbon films (carbon type-B 300 mesh, Beijing XXBR Technology Co., Ltd., China) at the GC rural and BJ urban sites using an individual particle sampler (DKL-2, Qingdao Genstar Electronic Technology Co., Ltd., China) at a flow rate of $1 \mathrm{~L} \mathrm{~min}^{-1}$. The DKL-2 sampler consists of a single-stage impactor with a $0.5 \mathrm{~mm}$ diameter jet nozzle. Sampling duration ranged from $8 \mathrm{~s}$ to $3 \mathrm{~min}$ depending on the pollution levels to avoid overlap of particles on the TEM grids. Individual particle samples were placed in a clean and airtight container with controlled temperature $\left(T, 25 \pm 1^{\circ} \mathrm{C}\right)$ and relative humidity (RH, $20 \pm 3 \%$ ) for further analyses. Detailed information about the individual particle samples collected at the two sites is listed in Table S1 in the Supplement.

Meteorological parameters including $T$, pressure $(P), \mathrm{RH}$, wind speed (WS), and wind direction (WD) were recorded every $5 \mathrm{~min}$ at two sampling sites using a pocket weather station (Kestrel 5500, Nielsen-Kellerman Inc., USA). Hourly concentrations of $\mathrm{PM}_{2.5}$ and gaseous pollutants (i.e., $\mathrm{SO}_{2}$, $\mathrm{NO}_{2}, \mathrm{CO}$, and $\mathrm{O}_{3}$ ) during the sampling period at two monitoring stations (i.e., Dingxing government station at $39^{\circ} 15^{\prime} 42^{\prime \prime} \mathrm{N}, 115^{\circ} 48^{\prime} 06^{\prime \prime} \mathrm{E}$; Beijing Olympic Center station at $40^{\circ} 00^{\prime} 11^{\prime \prime} \mathrm{N}, 116^{\circ} 24^{\prime} 25^{\prime \prime} \mathrm{E}$ ) close to GC rural and BJ urban sites were downloaded from the website of an air quality online monitoring and analysis platform (https://www. aqistudy.cn/, last access: 14 February 2021). All the data in this study are presented in Beijing local time (UTC+8).

\section{2 $\quad$ PM $_{2.5}$ chemical analysis}

$\mathrm{PM}_{2.5}$ samples collected at the GC rural site were analyzed to obtain their water-soluble inorganic ions (WSIIs), organic carbon (OC), and elemental carbon (EC). For the analysis of WSIIs, two $16 \mathrm{~mm}$ diameter punches from each $\mathrm{PM}_{2.5}$ sample were put into a vial, followed by adding $20 \mathrm{~mL}$ of deionized water $(18.2 \mathrm{M} \Omega)$. Then these vials were placed in an ultrasonic water bath for $30 \mathrm{~min}$ to extract WSIIs. The solutions were further filtered using PTFE syringe filters with a $0.45 \mu \mathrm{m}$ pore size to remove insoluble components and then analyzed by an ion chromatography system (Dionex ICS 600, Thermo Fisher Scientific, USA). Finally, concentrations of three anions $\left(\mathrm{Cl}^{-}, \mathrm{SO}_{4}^{2-}\right.$, and $\left.\mathrm{NO}_{3}^{-}\right)$and five cations $\left(\mathrm{Na}^{+}\right.$, $\mathrm{NH}_{4}^{+}, \mathrm{K}^{+}, \mathrm{Mg}^{2+}$, and $\mathrm{Ca}^{2+}$ ) were obtained. Concentrations of $\mathrm{OC}$ and $\mathrm{EC}$ in $\mathrm{PM}_{2.5}$ samples were determined by analyzing a $1 \times 1.5 \mathrm{~cm}^{2}$ punch from each filter with an OCEC analyzer (Model 5L, Sunset Laboratory Inc., USA), which adopted the NIOSH870 temperature protocol with thermaloptical transmittance for charring correction. The OM concentration was estimated via multiplying the OC concentration by a factor of 1.6, based on previous studies (Xing et al., 2013; Zheng et al., 2015).

\subsection{AMS data analysis}

The HR-AMS V-mode data were analyzed using standard data analysis software (PIKA v1.56D). A constant collection efficiency (CE) of 0.5 , similar to that of a previous study conducted in winter at the BJ site (Sun et al., 2014), was applied to the HR-AMS datasets to obtain mass concentrations of NR-PM $\mathrm{PM}_{1}$ species. The relative ionization efficiencies used for $\mathrm{OM}, \mathrm{SO}_{4}^{2-}, \mathrm{NO}_{3}^{-}, \mathrm{NH}_{4}^{+}$, and $\mathrm{Cl}^{-}$were 1.4 , $1.2,1.1,5.0$, and 1.3 , respectively. Positive matrix factorization (PMF) is a receptor model to identify potential sources without local source profiles provided (Xu et al., 2021). PMF was performed on the high-resolution mass spectra of organics measured by the HR-AMS. Six OA factors were identified including fossil-fuel-related OA (FFOA), cooking OA (COA), biomass burning OA (BBOA), oxidized primary OA (OPOA), oxygenated OA (OOA), and aqueous-phase OOA (aqOOA). Detailed information on the processing of HRAMS data can be found in a related paper during the same campaign (Xu et al., 2019).

\subsection{Individual particle analysis}

Individual particle samples were analyzed using TEM (JEM2100 , JEOL Ltd., Japan) operated at a $200 \mathrm{kV}$ accelerating voltage to acquire the morphology and sizes of individual particles and mixing state (i.e., internally or externally mixed) of different aerosol components within one individual particle. The TEM instrument is equipped with an energydispersive X-ray spectrometer (EDS; INCA X-Max ${ }^{\mathrm{N}} 80 \mathrm{~T}$, Oxford Instruments, UK) to semi-quantitatively detect the 

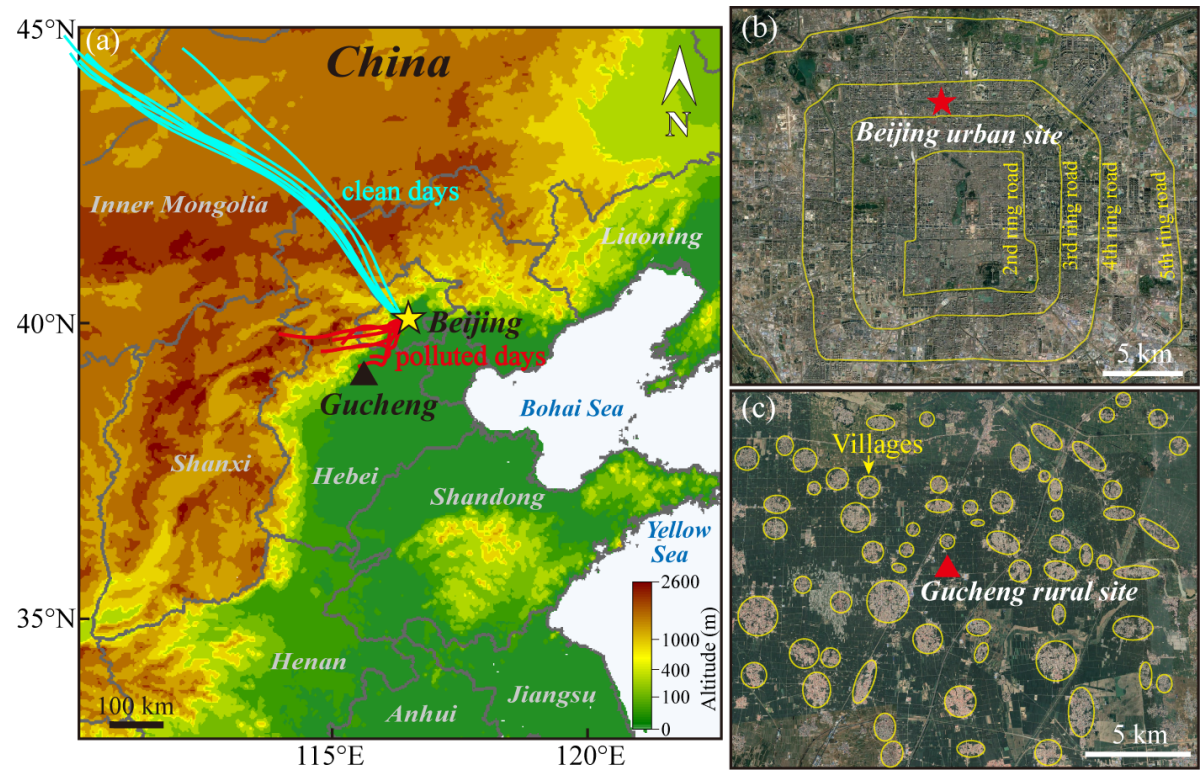

Figure 1. Locations of Beijing and Gucheng in the North China Plain (a) and the expanded view of surrounding topographies around the Beijing urban site (b) and Gucheng rural site (c). The $24 \mathrm{~h}$ backward trajectories of air masses ending at the height of $100 \mathrm{~m}$ a.g. 1 . over the Beijing urban site on clean days (20-23 November) and polluted days (24-27 November) during the observation are also shown in panel (a). Map copyright @ 2020 Google Maps.

elemental composition of individual particles with atomic number greater than six $(Z \geq 6)$. It should be noted that $\mathrm{Cu}$ peaks in the EDS spectra are not considered due to the interference from the $\mathrm{Cu}$ substrate of TEM grids. The distribution of aerosol particles on TEM grids is not uniform, with particle size decreasing from the center to the edge of the distribution area. Therefore, to ensure the analyzed particles are representative, five grid meshes from the center to the edge of the particle distribution area in each sample were selected to conduct TEM analysis. TEM images were manually processed by the RADIUS 2.0 software (EMSIS GmbH, Germany) to determine the particle types, areas, perimeters, and equivalent circle diameters (ECDs). After a labor-intensive operation, a total of 1197 particles at the BJ urban site and 2443 particles at the GC rural site were analyzed.

A scanning electron microscope (SEM; Ultra 55, Carl Zeiss Microscopy $\mathrm{GmbH}$, Germany) was operated at a $10 \mathrm{kV}$ accelerating voltage and in the secondary electron (SE2) mode to observe the particle surface topography. Furthermore, particles were imaged at a tilt angle of $75^{\circ}$ to realize the visualization of their morphology in the vertical dimension.

\subsection{Optical property calculation}

Mie theory has been widely used to calculate the optical properties of individual particles by assuming a spherical core-shell structure (Chylek et al., 2019; Wu et al., 2018; Yu et al., 2019). In this study, the light absorption cross sections (ACSs) of internally mixed POA particles with secondary in- organic aerosol (SIA) shell (named as core-shell POA-SIA particles), as well as the POA cores and bare POA particles at the wavelength of $550 \mathrm{~nm}$, were calculated with BHCOAT Mie code (Bohren and Huffman, 1983). For details of the classification of POA and POA-SIA particles, please refer to Sect. 3.2. For the core-shell POA-SIA particles, a refractive index (RI) of 1.55-0i for non-light-absorbing SIA coating (Denjean et al., 2014) and 1.67-0.27i for light-absorbing POA cores (Alexander et al., 2008) was adopted at the wavelength of $550 \mathrm{~nm}$; and the ECD of each POA-SIA particle and its POA core obtained from the TEM images were used as the input particle diameter $\left(D_{\mathrm{p}}\right)$ and core diameter $\left(D_{\mathrm{c}}\right)$, respectively, in the Mie calculation, which made the calculation sufficient to approximate reality. Because a core-shell structure is considered in the Mie model (Bond et al., 2006), for the uncoated POA particles (including POA cores without SIA shell and bare POA particles), the ECD of each POA particle and $1 / 10$ of it were input as the $D_{\mathrm{p}}$ and $D_{\mathrm{c}}$, respectively. Then in the case of causing the refractive index difference between the shell and core to vanish (i.e., POA core and POA shell, RI =1.67-0.27i), the Mie model can be applied to homogeneous particles. Besides, we also constructed models of core-shell POA-SIA particles with different POA core diameters (i.e., $D_{\mathrm{c}}=100,200,300,400,500,700,900$, 1100,1300 , and $1500 \mathrm{~nm}$ ) and particle-to-core diameter ratios (i.e., $D_{\mathrm{p}} / D_{\mathrm{c}}$ ranged from 1 to 6 with an interval of 0.1 ) and calculated their ACSs to further explore the effects of $D_{\mathrm{c}}$ and $D_{\mathrm{p}} / D_{\mathrm{c}}$ changes on the light absorption enhancement factors $\left(E_{\mathrm{abs}}\right)$ of POA particles. 
After running the Mie calculation, the attenuation efficiency $\left(Q_{\text {atn }}\right)$, scattering efficiency $\left(Q_{\text {sca }}\right)$, and absorption efficiency $\left(Q_{\mathrm{abs}}\right)$ of an individual particle were output with their definitions as follows (Aden and Kerker, 1951; Toon and Ackerman, 1981):

$$
\begin{aligned}
Q_{\mathrm{atn}} & =\left(\frac{2}{x^{2}}\right) \sum_{n=1}^{\infty}(2 n+1)\left[\operatorname{Re}\left(a_{n}+b_{n}\right)\right], \\
Q_{\text {sca }} & =\left(\frac{2}{x^{2}}\right) \sum_{n=1}^{\infty}(2 n+1)\left(\left|a_{n}\right|^{2}+\left|b_{n}\right|^{2}\right), \\
Q_{\text {abs }} & =Q_{\text {atn }}-Q_{\text {sca }},
\end{aligned}
$$

where $x=\frac{\pi D}{\lambda}$ is the dimensionless size parameter of the particle diameter $D$ and the wavelength of incident light $\lambda, a_{n}$ and $b_{n}$ are calculated from Riccati-Bessel functions of the particle sizes and refractive indices (Bohren and Huffman, 1983), and the symbol Re denotes the real part of the complex quantity $a_{n}+b_{n}$. The ACS of a particle can be obtained via multiplying the $Q_{\mathrm{abs}}$ by the geometric cross section of the particle shown as follows:

$$
\mathrm{ACS}=Q_{\mathrm{abs}} \times \frac{\pi D^{2}}{4} .
$$

\section{Results and discussion}

\subsection{Overview of a regional haze episode}

A typical regional heavy haze episode in the NCP was observed at the GC rural and $\mathrm{BJ}$ urban sites during 22-27 November 2016. Based on variations in hourly $\mathrm{PM}_{2.5}$ concentrations, three pollution levels are defined: clean $\left(\mathrm{PM}_{2.5} \leq 75 \mu \mathrm{g} \mathrm{m}^{-3}\right)$, moderate pollution $\left(75 \mu \mathrm{g} \mathrm{m}^{-3}<\mathrm{PM}_{2.5} \leq 200 \mu \mathrm{g} \mathrm{m}^{-3}\right)$, and heavy pollution $\left(\mathrm{PM}_{2.5}>200 \mu \mathrm{g} \mathrm{m}^{-3}\right)$. According to the above criteria, we classified a clean period (21 November 00:00 to 22 November 19:00) and heavily polluted period (22 November 20:00 to 27 November 10:00) at the GC rural site and a clean period (21 November 00:00 to 24 November 09:00), moderately polluted period (24 November 10:00 to 25 November 16:00), and heavily polluted period (25 November 17:00 to 27 November 02:00) at the BJ urban site (Fig. 2). Furthermore, we divided the heavily polluted period at the GC rural site into the early stage (22 November 20:00 to 23 November 20:00), middle stage (23 November 20:00 to 24 November 20:00), and late stage (24 November 20:00 to 27 November 08:00) based on the evolution of chemical species in $\mathrm{PM}_{2.5}$ (Fig. 2a). The average meteorological parameters and mass concentrations of $\mathrm{PM}_{2.5}$, aerosol chemical species, OA factors, and gaseous pollutants in different periods at two sampling sites are summarized in Table S2.

Strong northwesterly winds $\left(>4 \mathrm{~m} \mathrm{~s}^{-1}\right)$ accompanied by rain and snow invaded the NCP during 20-21 November (Fig. S1), leading to fast dispersion of air pollutants (Figs. 2 (a) Gucheng rural site

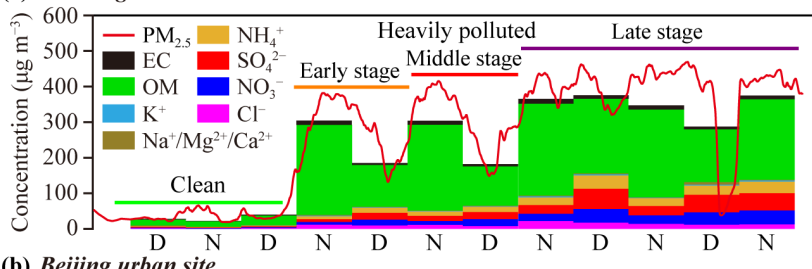

(b) Beijing urban site

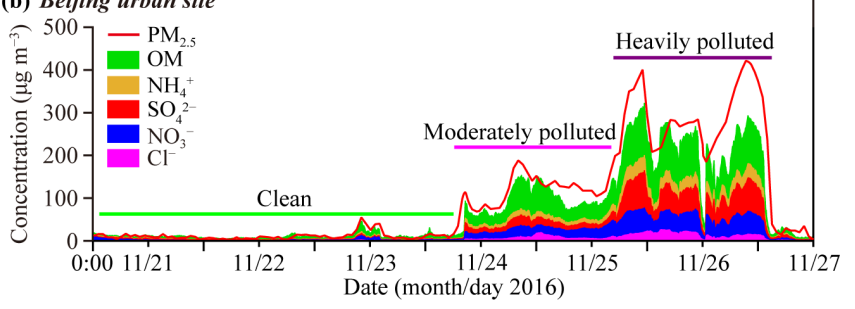

Figure 2. Time series of $\mathrm{PM}_{2.5}$ and major aerosol chemical species at the (a) Gucheng rural site and (b) Beijing urban site. Chemical species were obtained by offline analysis of daytime (D) and nighttime (N) $\mathrm{PM}_{2.5}$ filter samples at the rural site and were obtained by online analysis of NR-PM 1 using a high-resolution aerosol mass spectrometer (HR-AMS) at the urban site. The different periods of the haze episode at rural and urban sites are marked in this figure.

and S2). The low $T\left(-8\right.$ to $\left.5^{\circ} \mathrm{C}\right)$ and WS $\left(<2 \mathrm{~m} \mathrm{~s}^{-1}\right)$ were displayed after the cold front (Fig. S1), which can facilitate the accumulation of air pollutants (Zhong et al., 2019). At the $\mathrm{GC}$ rural site, $\mathrm{PM}_{2.5}$ concentration began to increase at 18:00 on 22 November and quickly reached a peak of $394 \mu \mathrm{g} \mathrm{m}^{-3}$ within $6 \mathrm{~h}$ (Fig. 2a). $\mathrm{PM}_{2.5}$ chemical analysis reveals that OM $\left(252.8 \mu \mathrm{g} \mathrm{m}^{-3}\right)$ accounted for $83 \%$ of the $\mathrm{PM}_{2.5}$ in the nighttime sample on 22 November (i.e., 22 November 20:00 to 23 November 08:00), causing the fast transition from the clean to heavily polluted period directly (Figs. 2a and S3a). In the early stage of the heavily polluted period, the average $\mathrm{PM}_{2.5}$ concentration $\left(288.3 \mu \mathrm{g} \mathrm{m}^{-3}\right)$ increased by a factor of 7 compared with that $\left(39.8 \mu \mathrm{g} \mathrm{m}^{-3}\right)$ in the clean period, with OM being the largest contributor $\left(185.1 \mu \mathrm{g} \mathrm{m}^{-3}\right)$ followed by SIAs (i.e., sum of $\mathrm{SO}_{4}^{2-}, \mathrm{NO}_{3}^{-}$, and $\mathrm{NH}_{4}^{+}$, which is $36.4 \mu \mathrm{g} \mathrm{m}^{-3}$ ) (Table S2). At the BJ urban site, the air quality remained clean before 24 November under continuous northerly winds (Figs. $2 \mathrm{~b}$ and $\mathrm{S} 1 \mathrm{~b}$ ). With prevailing winds changing from northerly to southerly on 24 November (Fig. S1), polluted air parcels in the south of the NCP were transported to Beijing (Fig. 1a), which has also been confirmed by another study conducted in the APHH-Beijing winter campaign (Du et al., 2019). Thus, the concentrations of $\mathrm{PM}_{2.5}$ and chemical species in NR-PM, $\mathrm{CO}$, and $\mathrm{SO}_{2}$ at the BJ urban site increased simultaneously and sharply from 09:00 on 24 November, causing the transition from the clean period to the moderately polluted period (Figs. 2b and S2b). The average $\mathrm{PM}_{2.5}$ concentration in the moderately polluted period was $111.0 \mu \mathrm{g} \mathrm{m}^{-3}, 10$ times higher than that $\left(10.8 \mu \mathrm{g} \mathrm{m}^{-3}\right)$ in the clean period, and the OM and SIAs contributed equally in NR-PM $\mathrm{PM}_{1}$ with their average concen- 
trations being 44.4 and $43.4 \mu \mathrm{g} \mathrm{m}^{-3}$, respectively (Table S2). Following the haze evolution, $\mathrm{PM}_{2.5}$ levels increased gradually to 312.3 and $396.8 \mu \mathrm{g} \mathrm{m}^{-3}$ in the middle and late stages of the heavily polluted period at the GC rural site and to $281.0 \mu \mathrm{g} \mathrm{m}^{-3}$ in the heavily polluted period at the BJ urban site (Fig. 2 and Table S2). Contrasting the above transition periods at two sampling sites, we found that the SIA concentration increased significantly; meanwhile, the OM concentration only slightly increased at the GC rural and BJ urban sites with the consistent decreasing WS and increasing RH during the heavily polluted period (Figs. 2 and S1). In a word, we observed that the SIA fraction in fine particles increased and the OM fraction decreased following the haze evolution (Fig. S3).

The concentrations and fractions of OM and EC at nighttime were much higher than those in the daytime during the whole haze episode at the GC rural site (Figs. 2a and S3a), suggesting continuous strong local combustion emissions at nighttime. Furthermore, the concentration of $\mathrm{Cl}^{-}(8-$ $\left.22 \mu \mathrm{g} \mathrm{m}^{-3}\right)$ was much higher than that of $\mathrm{K}^{+}\left(1-3 \mu \mathrm{g} \mathrm{m}^{-3}\right)$ (Fig. 2a), which suggests more contributions from coal combustion than from biomass burning at the GC rural site (Sun et al., 2014; Zhang et al., 2020). Based on the field investigation and $\mathrm{PM}_{2.5}$ analysis, we concluded that the explosive increase in $\mathrm{PM}_{2.5}$ at the GC rural site was initiated by strong local emissions and accumulation of POAs from residential coal combustion for heating and a small fraction of biomass burning for cooking in rural areas. The PMF analysis shows that FFOA and BBOA (14.6-30.6 $\left.\mu \mathrm{g} \mathrm{m}^{-3}\right)$ contributed significantly $(>30 \%)$ to $\mathrm{OM}$ in the polluted period at the BJ urban site (Fig. S4 and Table S2), suggesting that POAs emitted in rural areas were transported to Beijing under southerly winds. In summary, bulk analyses show that POAs from residential coal and biomass burning consistently contributed to the regional haze, and SIAs produced from the secondary formation had an increasing contribution at higher RH following the haze evolution.

\subsection{Classification of individual particle types}

In this study, TEM observations show abundant spherical and irregular particles comprised of $\mathrm{C}, \mathrm{O}$, and $\mathrm{Si}$ elements during this haze episode (Fig. 3a). These particles are stable under strong electron beams and appear as dark features in TEM images, reflecting their high thickness and refractory properties (Ebert et al., 2016; Liu et al., 2018). The SEM image acquired at a $75^{\circ}$ tilt angle shows that these particles did not deform upon impaction and retained high vertical dimensions (Fig. 4), indicating that they are in a solid state with high viscosity (Reid et al., 2018; Wang et al., 2016). By contrast, the secondary particles (i.e., SIAs and organic coating) became flat on the substrate (Fig. 4). Previous studies have confirmed that these solid spherical and irregular particles are POA particles emitted from coal and biomass burning (L. Liu et al., 2017; Zhang et al., 2018); in particular the spherical
POA particles as shown in Fig. 3a-1 are defined as tarballs containing light-absorbing $\mathrm{BrC}$ (Adachi et al., 2019; C. Li et al., 2019; Pósfai et al., 2003; Zhang et al., 2018). Both tarballs (Fig. 3a-1) and irregular POA particles (Fig. 3a-2) are burning-related POA particles and have similar chemical composition and physical characteristics under the TEM despite their different shapes; thus in this study, we consider irregular POA particles to also contain light-absorbing $\mathrm{BrC}$ like tarballs.

Other typical individual particle types, such as SIA (Fig. 3b), mineral (Fig. 3c), soot (Fig. 3d), and fly ash (Fig. 3e-1) and metal (Fig. 3e-2) particles, were also classified during this haze episode. The detailed classification criteria of these particle types derived from the TEM images and their sources can be found in our previous paper (Li et al., 2016a). It should be noted that some SIA particles were coated with secondary organic coatings (Fig. 3b) which were produced from the chemical oxidation of volatile organic compounds ( $\mathrm{Li}$ et al., 2016b). TEM observations further show the internal mixture of POA or soot particles with SIA particles, i.e., POA-SIA (Fig. 3f) and soot-SIA (Fig. 3g) particles. To better understand the number variations in different particle types, we classified bare POA and POA-SIA particles as the POA-containing particles and bare soot and soot-SIA particles as soot-containing particles.

\subsection{Relative abundance of individual particle types}

Figure 5 shows number fractions of different particle types in different periods at GC rural and BJ urban sites. At the GC rural site, $\mathrm{POA}$-containing and soot-containing particles were the major particle types with their corresponding contributions being $37.6 \%$ and $35.9 \%$ by number, followed by SIA particles $(22.4 \%)$ in the clean period. When the haze episode occurred at the GC rural site, POA-containing particles became dominant in the early stage of the heavily polluted period and its number fraction $(64.8 \%)$ was nearly twice that $(37.6 \%)$ in the clean period (Fig. 5a). This result agrees well with the bulk $\mathrm{PM}_{2.5}$ analysis which shows a sharp increase in OM concentration in the early stage of the heavily polluted period (Fig. 2a). With increasing pollution levels from the early stage to the late stage of the heavily polluted period, the fraction of POA-containing particles slightly decreased from $64.8 \%$ to $50.8 \%$; by contrast, the fraction of SIA particles increased from $4.6 \%$ to $12.4 \%$ (Fig. 5a). The variations in POA-containing and SIA particles are similar to the results from the bulk $\mathrm{PM}_{2.5}$ analysis as shown in Fig. 2a.

At the BJ urban site, the contribution of POA-containing particles $(15.1 \%)$ in the clean period was much lower than that $(37.6 \%)$ at the GC rural site (Fig. 5). Following the transition from the clean period to the moderately polluted period at the BJ urban site, the fraction of POA-containing particles $(66.2 \%)$ increased significantly by more than a factor of 4 compared with that $(15.1 \%)$ in the clean period. Meanwhile, fractions of soot-containing, mineral, and SIA parti- 


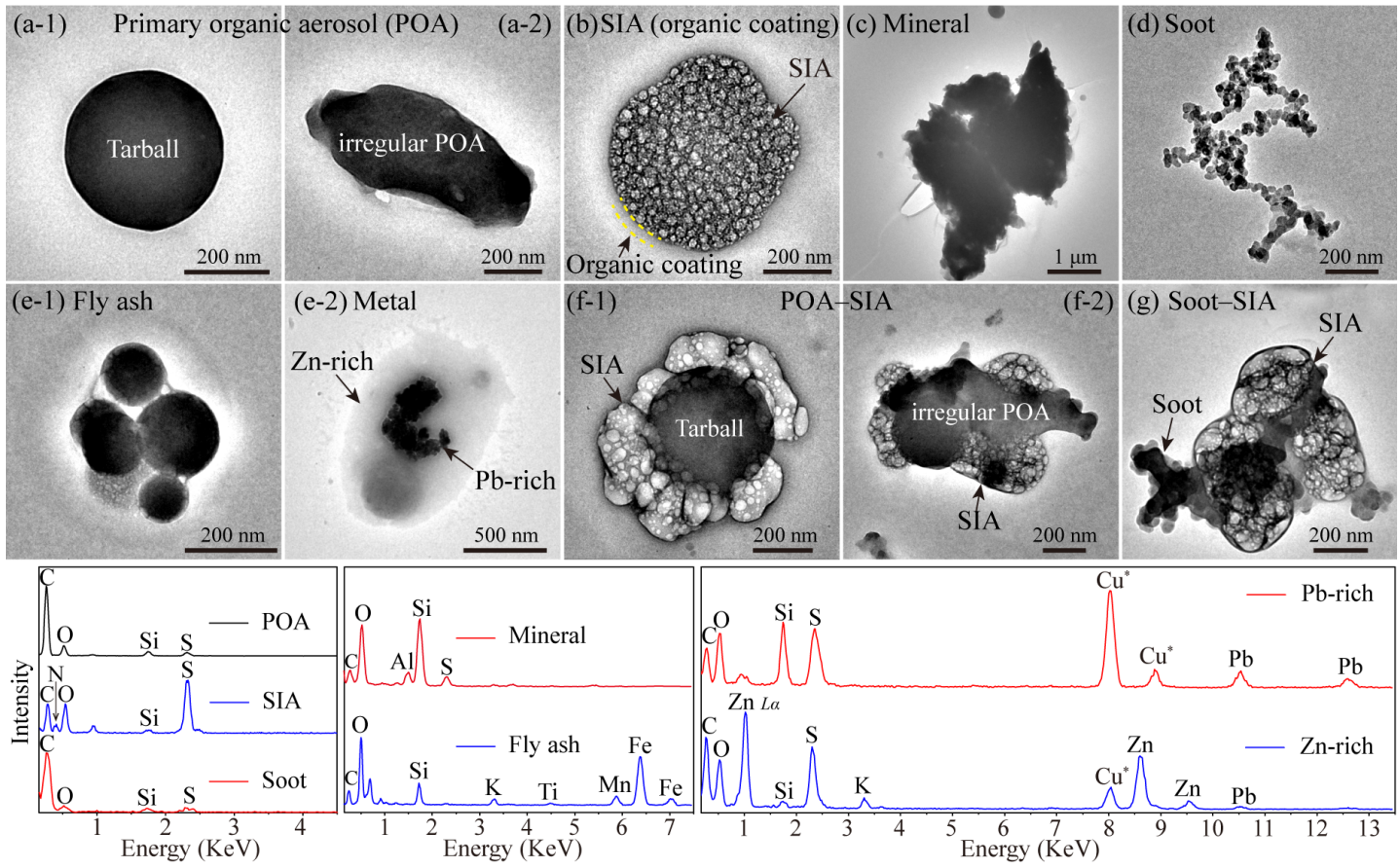

Figure 3. Typical transmission electron microscopy (TEM) images and energy-dispersive X-ray spectrometer (EDS) spectra showing the morphology, composition, and mixing structures of different individual particle types. (a) Primary organic aerosol (POA) particles with (a1) spherical (i.e., tarball) or (a-2) irregular shapes; (b) secondary inorganic aerosol (SIA) particle with secondary organic coating; (c) mineral; (d) soot; (e-1) fly ash and (e-2) metal; (f) internally mixed POA particle with SIA coating (POA-SIA); (g) internally mixed soot particle with SIA coating (soot-SIA).

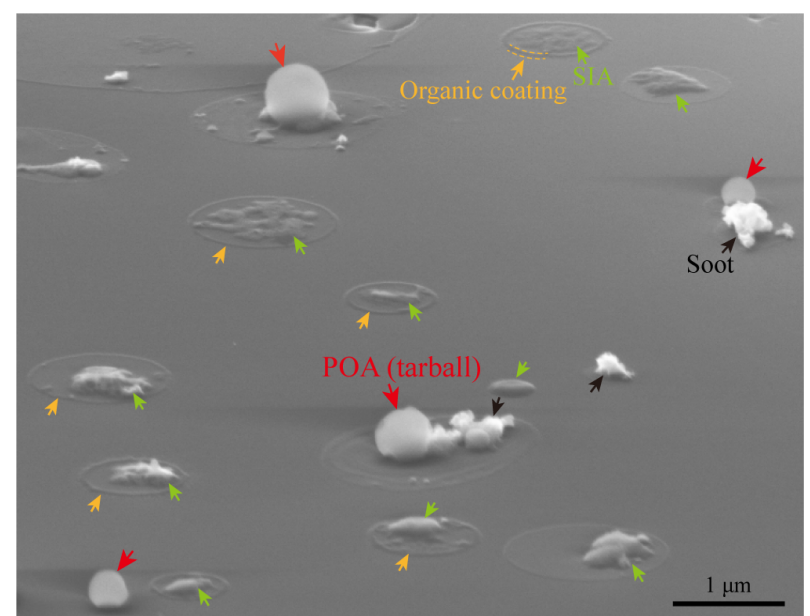

Figure 4. Scanning electron microscope (SEM) image acquired in the secondary electron (SE2) mode at a $75^{\circ}$ tilt angle showing the surface morphology of individual particles in the vertical dimension. The red, black, green, and orange arrows indicate primary organic aerosol (POA) particles (mainly tarballs), soot particles, secondary inorganic aerosol (SIA) particles, and secondary organic coating, respectively.

cles largely decreased. When the pollution level changed to the heavily polluted period, similarly to the situation at the
GC rural site, the fraction of SIA particles increased from $7.8 \%$ to $13.2 \%$ and the fraction of POA-containing particles decreased slightly from $66.2 \%$ to $52.8 \%$ (Fig. 5 b). Overall, the individual particle analysis results agree well with changes in aerosol chemical components obtained by the bulk analysis as shown in Fig. 2. Furthermore, individual particle analysis reveals that POA-containing particles dominated ( $>50 \%$ by number) in the rural and urban air during the regional wintertime haze episode.

\subsection{Atmospheric aging of POA particles}

TEM images clearly show the morphology and mixing state of individual particles in different polluted periods at GC rural and BJ urban sites (Fig. 6). At the GC rural site, we found that large numbers of bare POA particles, especially tarballs, occurred in the early stage of the heavily polluted period (Fig. 6a). Based on the integrated analyses of individual particles and bulk samples, we confirmed that POA particles emitted from the intense domestic coal and biomass burning for heating and cooking contributed significantly to the deterioration of air quality in rural areas. When the haze episode evolved into the late stage of the heavily polluted period, we found that most of the POA particles were coated with SIA (i.e., POA-SIA particle) forming the core-shell structure (Fig. 6b). This result indicates that POA particles in the 

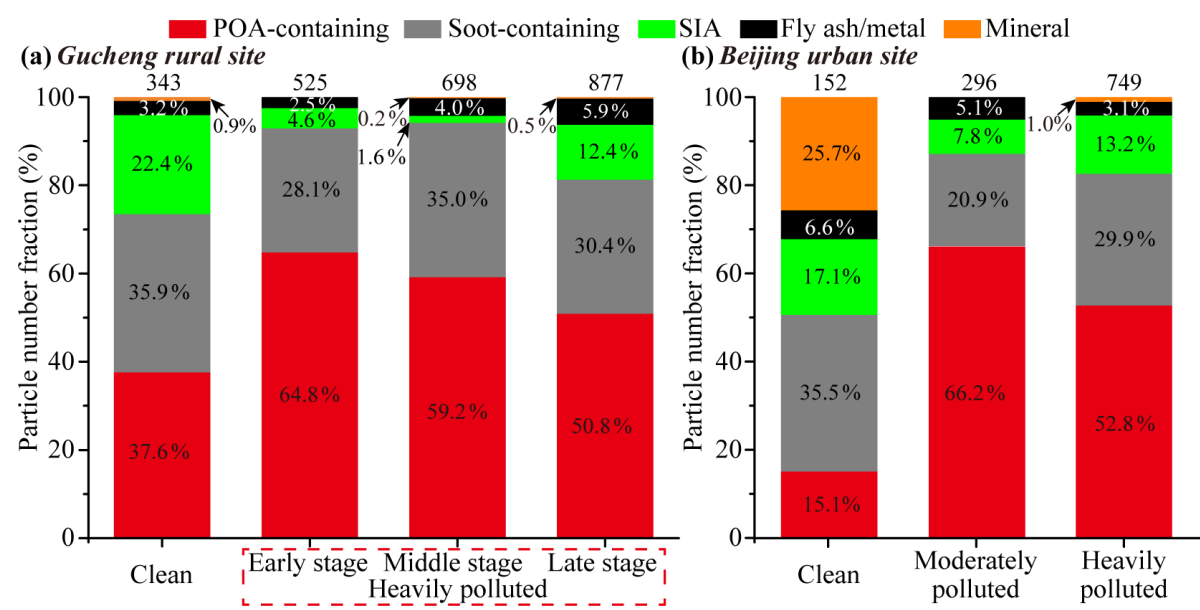

Figure 5. Relative abundance of different particle types in different periods at the (a) Gucheng rural site and (b) Beijing urban site. The numbers of analyzed particles in different periods are shown at the top of each column.

regional haze layer provided surfaces for the heterogeneous reactions of $\mathrm{SO}_{2}$ and $\mathrm{NO}_{x}$, which promotes the formation of SIA on POA particles in the humid polluted air (Ebert et al., 2016; Zhang et al., 2017).

Following the regional transport of polluted air masses from the south to the north of the NCP, abundant POA particles occurred in the moderately polluted period at the $\mathrm{BJ}$ urban site (Fig. 6c). Therefore, we conclude that the POA particles emitted in the rural areas in the south of the NCP could be transported to the BJ urban site and significantly affect the urban air quality. Following the haze evolution, similarly to those at the GC rural site, the POA particles aged and became core-shell POA-SIA particles at the BJ urban site in the heavily polluted period (Fig. 6d).

Based on the mixing state of POA-containing particles, we found that following evolution of the haze episode, the fraction of bare POA particles was reduced by a factor of 2 from $91.4 \%$ in the early stage to $39.6 \%$ in the late stage of heavily polluted period at the GC rural site, and the fraction of POA-SIA particles correspondingly increased by a factor of 7 from $8.6 \%$ to $60.4 \%$ (pie charts in Fig. 7). Similarly, at the BJ urban site, the fraction of bare POA particles decreased from $70.4 \%$ in the moderately polluted period to $31.4 \%$ in the heavily polluted period, and the fraction of POA-SIA particles increased correspondingly from $29.6 \%$ to $68.6 \%$ (pie charts in Fig. 7). Consequently, the average size of POAcontaining particles increased from $505 \mathrm{~nm}$ in the early stage to $837 \mathrm{~nm}$ in the late stage of the heavily polluted period at the GC rural site and from $443 \mathrm{~nm}$ in the moderately polluted period to $732 \mathrm{~nm}$ in the heavily polluted period at the BJ urban site (Fig. 7a). Interestingly, the average sizes of uncoated POA particles (i.e., POA cores and bare POA particles) remained similar following the haze evolution, with their respective values being 469,508 , and $465 \mathrm{~nm}$ in the early, middle, and late stages of the heavily polluted period at the GC rural site and 381 and $379 \mathrm{~nm}$ in the moderately and heavily polluted periods at the BJ urban site (Fig. 7b). The average sizes of uncoated POA particles at the BJ urban site were slightly smaller than those at the GC rural site, which is reasonable because the fresh POA particles with larger sizes could be collected at the GC rural site close to emission sources and larger ones are more likely to be removed during the regional transport (Seinfeld and Pandis, 2006). Adachi et al. (2018) reported that tarballs retained their spherical shapes and the particle masses and sizes did not change largely when heated to $300^{\circ} \mathrm{C}$ under TEM. As a result, we conclude that the POA particles should be quite physically stable and chemically inert in the atmosphere and can be transported over long distances.

The $D_{\mathrm{p}} / D_{\mathrm{c}}$ ratio can be used to indicate the aging degree of POA-containing particles in the atmosphere (Chen et al., 2017; Li et al., 2011). By calculating the $D_{\mathrm{p}} / D_{\mathrm{c}}$ ratio, we realized quantification of the aging degree of POA-containing particles as shown in Fig. 8. In the early stage of the heavily polluted period at the GC rural site, the POA-containing particles were mainly fresh bare POA particles with a fraction of $91.4 \%$ (Fig. 7); therefore, the average $D_{\mathrm{p}} / D_{\mathrm{c}}$ ratio was close to 1 (1.02). Following the haze evolution at the GC rural and BJ urban sites, average $D_{\mathrm{p}} / D_{\mathrm{c}}$ ratios increased from 1.08 in the middle stage to 1.60 in the late stage of the heavily polluted period at the GC rural site and from 1.11 in the moderately polluted period to 1.67 in the heavily polluted period at the BJ urban site. The results indicate that POA particles were thickly coated with SIA particles due to the particle aging process. Here we can obtain two conclusions based on the individual particle analysis: (1) more POA particles continuously aged and were coated with SIA particles following the haze evolution; (2) the SIA coating gradually grew through the heterogeneous conversion of gaseous precursors (e.g., $\mathrm{SO}_{2}$ and $\mathrm{NO}_{x}$ ) in the polluted air. Therefore, the aging process of individual POA particles in wintertime hazes reflects well the regional haze evolution in the NCP. 


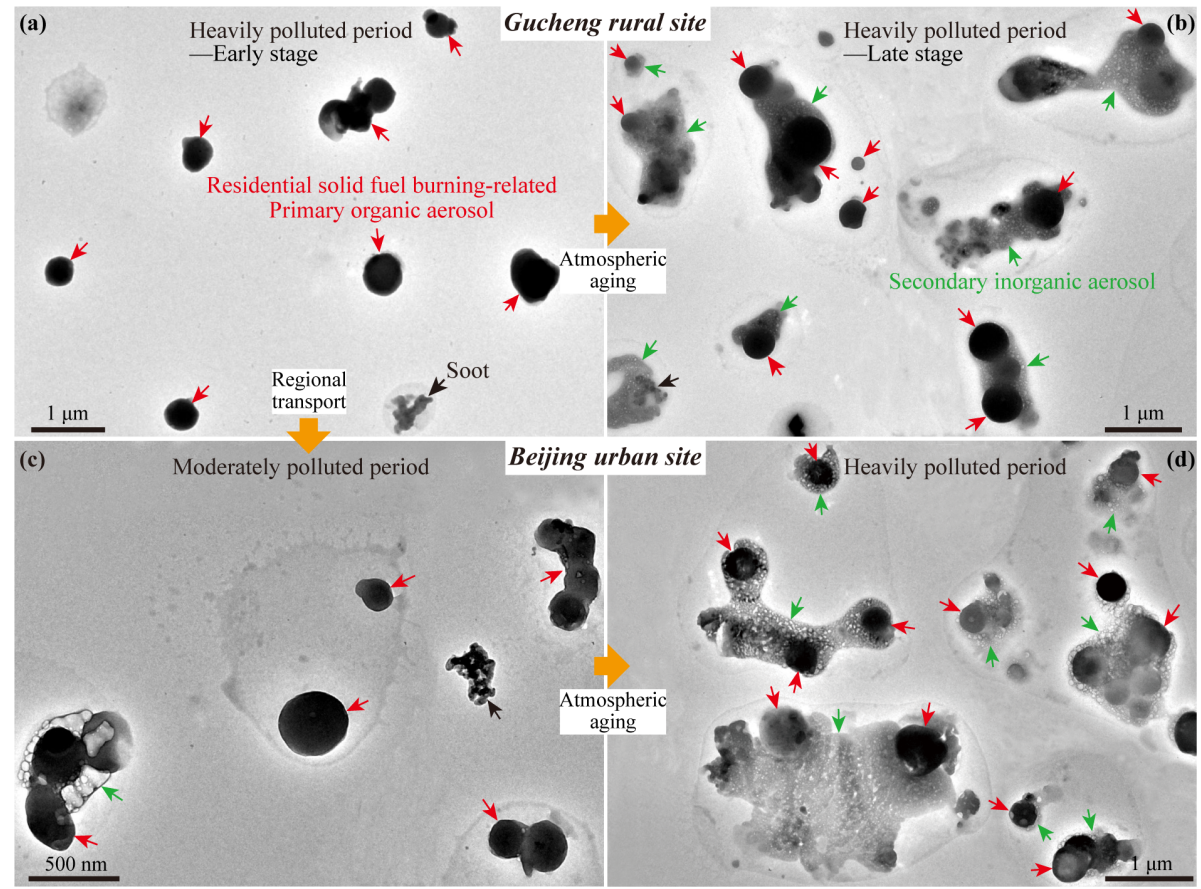

Figure 6. TEM images showing individual particles collected in the (a) early stage and (b) late stage of the heavily polluted period at the Gucheng rural site and in the (c) moderately polluted and (d) heavily polluted periods at the Beijing urban site. The red, green, and black arrows indicate primary organic aerosol (POA) particles, secondary inorganic aerosol (SIA) particles, and soot particles, respectively.

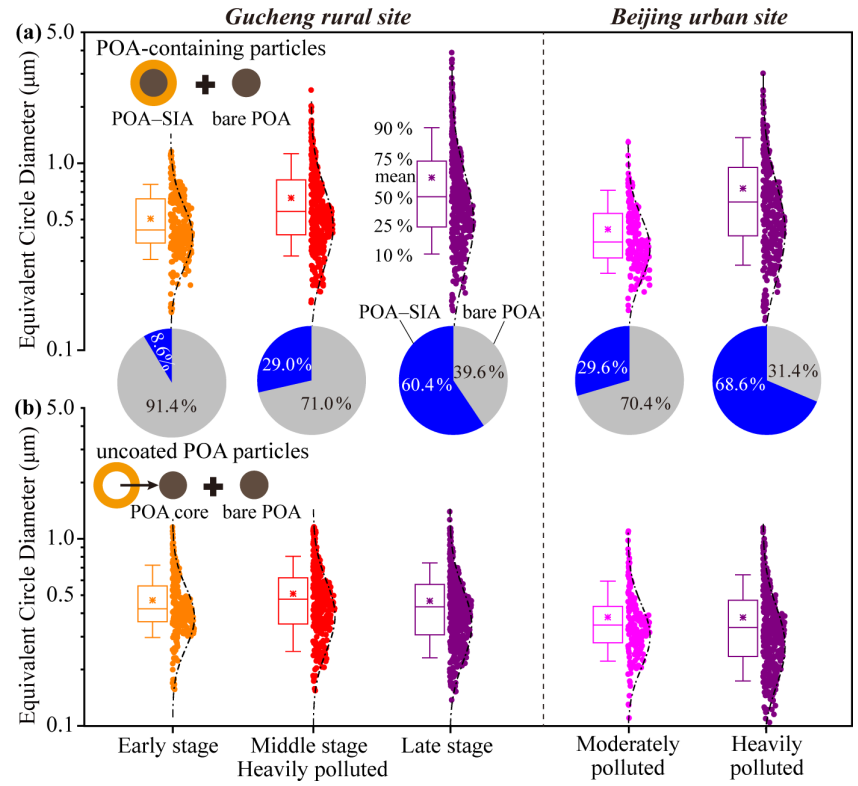

Figure 7. Box plots showing equivalent circle diameters (ECDs) of (a) POA-containing particles (including core-shell POA-SIA and bare POA) and (b) uncoated POA particles (including POA cores without SIA shell and bare POA) in different polluted periods at the Gucheng rural site and Beijing urban site. The solid circles (right of the boxes) represent the ECDs of individual particles with lognormal distributions. The pie charts present the relative number fractions between POA-SIA and bare POA particles in different polluted periods.

\subsection{Changes in light absorption of POA particles}

It is well known that organic aerosols emitted from coal and biomass burning are the main source of light-absorbing $\mathrm{BrC}$ (M. Li et al., 2019; Lin et al., 2016; Sun et al., 2017). Recently, some observation and modeling works have shown that $\mathrm{BrC}$ in haze layers over the NCP can affect the regional energy budget (Feng et al., 2013; Wang et al., 2018; Xie et al., 2019). However, there is no answer to how the aging process of burning-related light-absorbing POA particles influences their optical absorption in the regional haze. Here using Mie theory we further explored variations in the optical absorption of individual POA particles following the haze evolution at the GC rural and BJ urban sites (Fig. 9). It should be noted that another RI of 1.84-0.21i for tarballs was reported by Hoffer et al. (2016). The average Mie calculation results at the GC rural and BJ urban sites obtained by the RIs of $1.67-0.27 i$ (used in this study) and $1.84-0.21 i$ were compared, and we found that the two RIs only cause small differences between the results (Table S3). Therefore, only the results from the RI of $1.67-0.27 i$ were used and discussed in this study.

At the GC rural site, the average ACSs of individual POAcontaining particles under the actual scenario $\left(\mathrm{ACS}_{\text {actual }}\right)$ in the early, middle, and late stages of the heavily polluted period were estimated to be $3.09 \times 10^{-14}, 3.97 \times 10^{-14}$, and $4.43 \times 10^{-14} \mathrm{~m}^{2}$, respectively (Fig. 9a). If all the POAcontaining particles were not coated with SIA particles in 
(a) Gucheng rural site
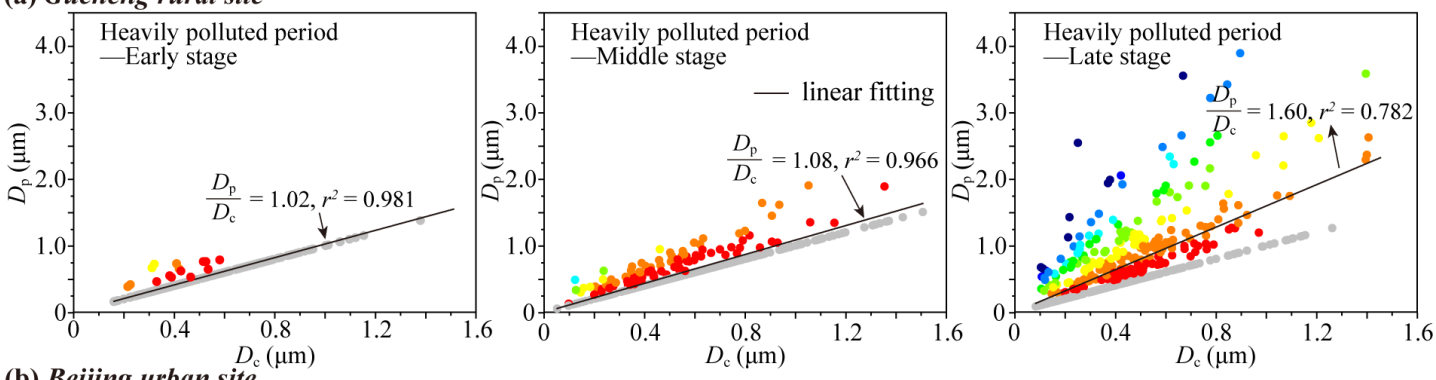

(b) Beijing urban site
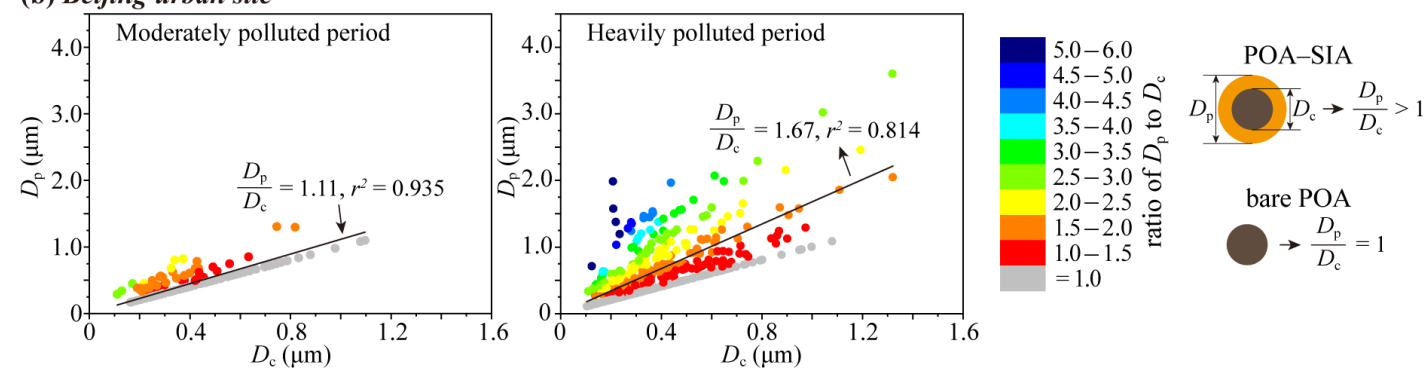

Figure 8. Relationship between the diameter of a POA-containing particle $\left(D_{\mathrm{p}}\right)$ and its POA core $\left(D_{\mathrm{c}}\right)$ in the early stage, middle stage, and late stage of the heavily polluted period at the Gucheng rural site (a) and in the moderately polluted and heavily polluted periods at the Beijing urban site (b).

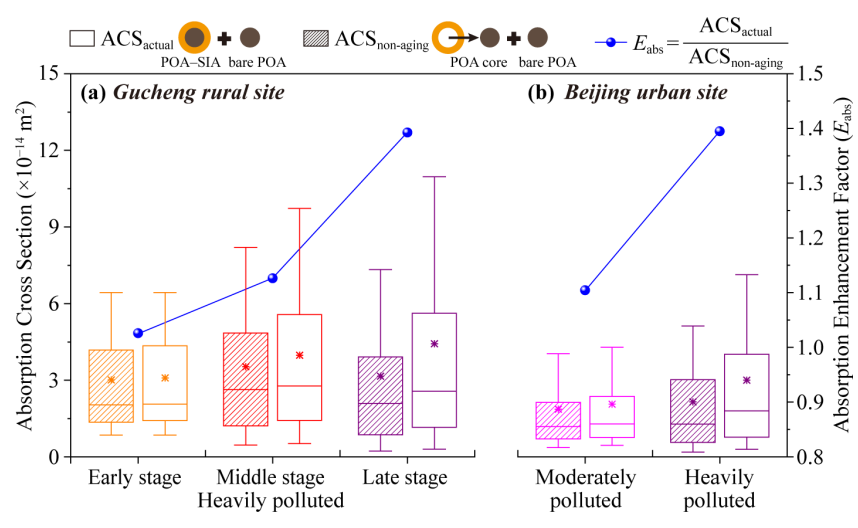

Figure 9. Box plots of light absorption cross sections (ACSs) of individual POA-containing particles (including core-shell POA-

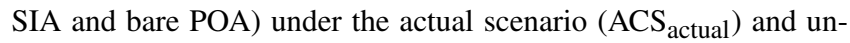
coated POA particles (including POA cores without SIA shell and bare $\mathrm{POA}$ ) under the particle non-aging scenario $\left(\mathrm{ACS}_{\text {non-aging }}\right)$ at a wavelength of $550 \mathrm{~nm}$ and variations in the light absorption enhancement factors ( $E_{\mathrm{abs}}$, i.e., ratio of $\mathrm{ACS}_{\text {actual }}$ to $\mathrm{ACS}_{\text {non-aging }}$ ) in different polluted periods at the (a) Gucheng rural site and (b) Beijing urban site. A refractive index of 1.55-0i for non-lightabsorbing SIA coating (Denjean et al., 2014) and 1.67-0.27i for light-absorbing POA cores (Alexander et al., 2008) were adopted at a wavelength of $550 \mathrm{~nm}$. The box represents the 25 th (lower line), 50th (middle line), and 75th (top line) percentiles; the asterisk in the box represents the mean value; and the end lines of the vertical bars represent the 10th (below the box) and 90th (above the box) percentiles. each period (i.e., particle non-aging scenario), the corresponding average ACSs of individual uncoated POA particles $\left(\mathrm{ACS}_{\text {non-aging }}\right)$ were $3.01 \times 10^{-14}, 3.53 \times 10^{-14}$, and $3.18 \times 10^{-14} \mathrm{~m}^{2}$, respectively (Fig. 9a). Therefore, we established that the $E_{\text {abs }}$ values (i.e., ratios of $\mathrm{ACS}_{\text {actual }}$ to $\left.\mathrm{ACS}_{\text {non-aging }}\right)$ were $1.02,1.12$, and 1.39 in the early, middle, and late stages of the heavily polluted period, respectively, at the GC rural site (Fig. 9a). Similarly, at the BJ urban site, the $E_{\text {abs }}$ values were 1.10 and 1.39 in the moderately and heavily polluted periods, respectively, with the corresponding average $\mathrm{ACS}_{\text {actual }}$ values being $2.06 \times 10^{-14}$ and $3.00 \times 10^{-14} \mathrm{~m}^{2}$ and $\mathrm{ACS}_{\text {non-aging values being } 1.86 \times 10^{-14}}$ and $2.15 \times 10^{-14} \mathrm{~m}^{2}$ (Fig. 9b). The light absorption capacity of individual POA particles at the BJ urban site was a little lower than that at the GC rural site (Fig. 9), which was mainly attributed to the smaller sizes of POA particles at the BJ urban site (Fig. 7).

To better understand the influence of SIA coating thickness and POA core diameter on the light absorption of POASIA particles, we modeled the variations in $E_{\text {abs }}$ of POA-SIA particles (i.e., ratio of ACS $\mathrm{POA}_{\mathrm{POA}}$ to $\mathrm{ACS}_{\mathrm{POA} \text { core }}$ ) with different $D_{\mathrm{c}}$ values as a function of $D_{\mathrm{p}} / D_{\mathrm{c}}$ ratios (Fig. 10). Results show that $E_{\text {abs }}$ is sensitive to the changes in both $D_{\mathrm{c}}$ and the $D_{\mathrm{p}} / D_{\mathrm{c}}$ ratio. When $D_{\mathrm{p}} / D_{\mathrm{c}}<1.5, E_{\mathrm{abs}}$ increases sharply with the increase in the $D_{\mathrm{p}} / D_{\mathrm{c}}$ ratio for different POA core sizes; but when $D_{\mathrm{p}} / D_{\mathrm{c}}>1.5, E_{\mathrm{abs}}$ no longer shows an increase for particles with $D_{\mathrm{c}}>200 \mathrm{~nm}$ and $E_{\text {abs }}$ is limited to between 1.5 and 2 for particles with $D_{\mathrm{c}}$ values ranging from 200 to $1500 \mathrm{~nm}$ (Fig. 10). The diameters of observed POA cores at the GC rural and BJ urban sites in this study 


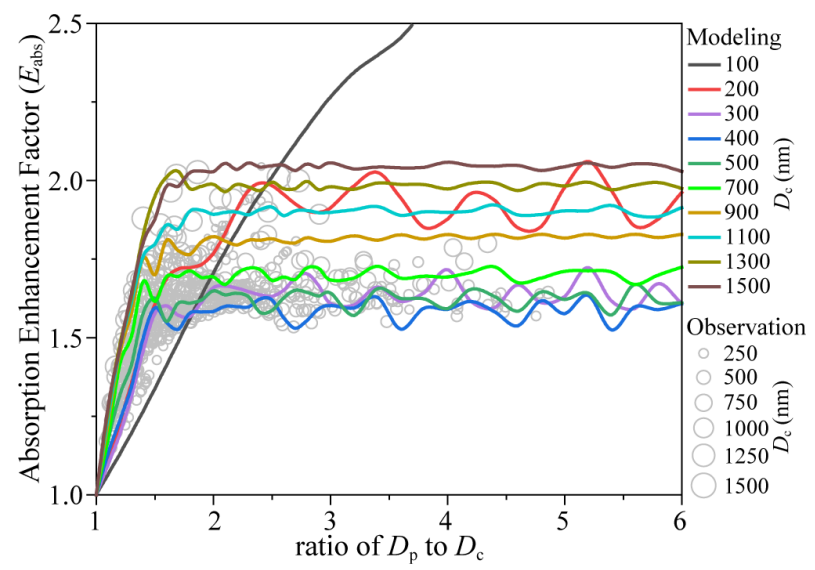

Figure 10. Mie-theory-calculated light absorption enhancement factors $\left(E_{\mathrm{abs}}\right)$ of modeled core-shell POA-SIA particles (i.e., ratio of ACS $\mathrm{POA}_{\mathrm{SIA}}$ to $\mathrm{ACS}_{\mathrm{POA}}$ core $)$ with different POA core diameters $\left(D_{\mathrm{c}}\right)$ as a function of the particle-to-core diameter ratio $\left(D_{\mathrm{p}} / D_{\mathrm{c}}\right)$ at a wavelength of $550 \mathrm{~nm}$ (solid lines). A refractive index of 1.55-0i for non-light-absorbing SIA coating (Denjean et al., 2014) and 1.67-0.27i for light-absorbing POA cores (Alexander et al., 2008) were adopted at a wavelength of $550 \mathrm{~nm}$. The open circles represent all the observed POA-SIA particles during all the polluted periods at the Gucheng rural and Beijing urban sites.

were mainly in the range of 200 to $800 \mathrm{~nm}$ (Fig. 7); thus the $E_{\text {abs }}$ values of observed POA-SIA particles in the NCP were mostly below 1.75 (Fig. 10). All the above results indicate that the atmospheric aging process could significantly improve the light absorption capacity of POA particles along with the evolution of haze episodes due to the lensing effect of SIA coating.

\section{Conclusions and implications}

This study demonstrates that primary pollutants, especially large numbers of POA particles emitted from the residential coal and biomass burning in rural areas, initiated a wintertime regional haze episode in the NCP. The presence of abundant burning-related POA particles in the atmosphere could further provide surfaces for heterogeneous reactions promoting the large production of SIA particles under stagnant meteorological conditions with high RH, which further elevated the pollution level. Compared with the tarballs which have been confirmed as $\mathrm{BrC}$ with strong light-absorbing capacities in previous studies (Adachi et al., 2019; C. Li et al., 2019), the spherical POA (i.e., tarball) and irregular POA particles observed in this study can better represent burningrelated light-absorbing primary organic particles in the wintertime hazes. Therefore, the ubiquitous light-absorbing POA particles in the atmosphere of the NCP unquestionably affect the energy balance (Feng et al., 2013). We found that burning-related POA particles remained quite stable during regional transport from the rural areas to urban Beijing in the
$\mathrm{NCP}$ and were coated with SIA particles through the atmospheric aging process in the haze layer, which could significantly enhance the light absorption capacity of POA particles via the lensing effect of SIA coating. We estimated that $E_{\text {abs }}$ values were within the upper limit of 1.75 in coreshell Mie calculations considering the typical size distribution of POA particles $(200-800 \mathrm{~nm})$ in the NCP. Furthermore, Alexander et al. (2008) found plenty of primary brown carbon spheres with a strong light absorption capacity in East Asian outflow, which indicates that the POA particles could be transported over long distances and still retain their strong light-absorbing properties and thus can affect regional and even global radiative forcing. Therefore, we highlight that the lensing effect, which has been adequately reported for $\mathrm{BC}$ particles but not for light-absorbing POA particles in previous studies, should be further considered on these POA particles in radiative forcing models.

Considering the adverse effects of residential coal and biomass burning on haze formation and climate change, we suggest that authorities should continue to implement "clean air actions" (Zhang and Geng, 2019) and especially encourage the use of clean energy such as electricity and natural gas for heating and cooking in rural areas of North China in winter.

Data availability. All data presented in this paper are available upon request. Please contact the corresponding author (liweijun@zju.edu.cn).

Supplement. The supplement related to this article is available online at: https://doi.org/10.5194/acp-21-2251-2021-supplement.

Author contributions. WL and LL designed the research. LL performed the data analysis and wrote the manuscript, and WL revised it. JZ and YZ assisted with the sample collection. YS provided the AMS data at the Beijing site. LL, JZ, YZ, LX, QY, and YW carried out the chemical analysis of $\mathrm{PM}_{2.5}$ and TEM analysis of individual particles. ZS, YS, DL, and PF contributed to the improvement of this paper. All the authors approved the final version of this paper.

Competing interests. The authors declare that they have no conflict of interest.

Special issue statement. This article is part of the special issue "In-depth study of air pollution sources and processes within Beijing and its surrounding region (APHH-Beijing) (ACP/AMT interjournal SI)". It is not associated with a conference.

Acknowledgements. We acknowledge the NOAA Air Resources Laboratory for the provision of the HYSPLIT transport and disper- 
sion model and READY website (http://www.ready.noaa.gov, last access: 14 February 2021) used in this paper. We thank the two anonymous referees of this paper for their helpful comments.

Financial support. This research has been supported by the National Natural Science Foundation of China (grant nos. 42075096 and 91844301), the National Key R\&D Program of China (grant no. 2017YFC0212700), the Zhejiang Provincial Natural Science Foundation of China (grant no. LZ19D050001), the China Postdoctoral Science Foundation (grant no. 2020M681823), and the UK Natural Environment Research Council (grant nos. NE/S00579X/1 and NE/N007190/1).

Review statement. This paper was edited by Yongjie Li and reviewed by two anonymous referees.

\section{References}

Adachi, K., Sedlacek, A. J., Kleinman, L., Chand, D., Hubbe, J. M., and Buseck, P. R.: Volume changes upon heating of aerosol particles from biomass burning using transmission electron microscopy, Aerosol Sci. Tech., 52, 46-56, https://doi.org/10.1080/02786826.2017.1373181, 2018.

Adachi, K., Sedlacek, A. J., Kleinman, L., Springston, S. R., Wang, J., Chand, D., Hubbe, J. M., Shilling, J. E., Onasch, T. B., Kinase, T., Sakata, K., Takahashi, Y., and Buseck, P. R.: Spherical tarball particles form through rapid chemical and physical changes of organic matter in biomassburning smoke, P. Natl. Acad. Sci. USA, 116, 19336-19341, https://doi.org/10.1073/pnas.1900129116, 2019.

Aden, A. L. and Kerker, M.: Scattering of Electromagnetic Waves from Two Concentric Spheres, J. Appl. Phys., 22, 1242-1246, https://doi.org/10.1063/1.1699834, 1951.

Alexander, D. T. L., Crozier, P. A., and Anderson, J. R.: Brown carbon spheres in East Asian outflow and their optical properties, Science, 321, 833-836, https://doi.org/10.1126/science.1155296, 2008.

Bohren, C. F. and Huffman, D. R.: Absorption and scattering of light by small particles, John Wiley \& Sons, New York, USA, 1983.

Bond, T. C., Habib, G., and Bergstrom, R. W.: Limitations in the enhancement of visible light absorption due to mixing state, J. Geophys. Res.-Atmos., 111, D20211, https://doi.org/10.1029/2006jd007315, 2006.

Bond, T. C., Doherty, S. J., Fahey, D., Forster, P., Berntsen, T., DeAngelo, B., Flanner, M., Ghan, S., Kärcher, B., and Koch, D.: Bounding the role of black carbon in the climate system: A scientific assessment, J. Geophys. Res.-Atmos., 118, 5380-5552, https://doi.org/10.1002/jgrd.50171, 2013.

Chakrabarty, R. K. and Heinson, W. R.: Scaling Laws for Light Absorption Enhancement Due to Nonrefractory Coating of Atmospheric Black Carbon Aerosol, Phys. Rev. Lett., 121, 218701, https://doi.org/10.1103/PhysRevLett.121.218701, 2018.

Chang, X., Wang, S., Zhao, B., Cai, S., and Hao, J.: Assessment of inter-city transport of particulate matter in the Beijing-
Tianjin-Hebei region, Atmos. Chem. Phys., 18, 4843-4858, https://doi.org/10.5194/acp-18-4843-2018, 2018.

Chen, S., Xu, L., Zhang, Y., Chen, B., Wang, X., Zhang, X., Zheng, M., Chen, J., Wang, W., Sun, Y., Fu, P., Wang, Z., and Li, W.: Direct observations of organic aerosols in common wintertime hazes in North China: insights into direct emissions from Chinese residential stoves, Atmos. Chem. Phys., 17, 1259-1270, https://doi.org/10.5194/acp-17-1259-2017, 2017.

Chen, X., Wang, H., Lu, K., Li, C., Zhai, T., Tan, Z., Ma, X., Yang, X., Liu, Y., Chen, S., Dong, H., Li, X., Wu, Z., Hu, M., Zeng, L., and Zhang, Y.: Field Determination of Nitrate Formation Pathway in Winter Beijing, Environ. Sci. Technol., 54, 9243-9253, https://doi.org/10.1021/acs.est.0c00972, 2020.

Cheng, Y., Zheng, G., Wei, C., Mu, Q., Zheng, B., Wang, Z., Gao, M., Zhang, Q., He, K., Carmichael, G., Pöschl, U., and Su, H.: Reactive nitrogen chemistry in aerosol water as a source of sulfate during haze events in China, Science Advances, 2, e1601530, https://doi.org/10.1126/sciadv.1601530, 2016.

Chylek, P., Lee, J. E., Romonosky, D. E., Gallo, F., Lou, S., Shrivastava, M., Carrico, C. M., Aiken, A. C., and Dubey, M. K.: Mie Scattering Captures Observed Optical Properties of Ambient Biomass Burning Plumes Assuming Uniform Black, Brown, and Organic Carbon Mixtures, J. Geophys. Res.-Atmos., 124, 11406-11427, https://doi.org/10.1029/2019jd031224, 2019.

Denjean, C., Formenti, P., Picquet-Varrault, B., Katrib, Y., Pangui, E., Zapf, P., and Doussin, J. F.: A new experimental approach to study the hygroscopic and optical properties of aerosols: application to ammonium sulfate particles, Atmos. Meas. Tech., 7, 183-197, https://doi.org/10.5194/amt-7-183-2014, 2014.

Du, H., Li, J., Chen, X., Wang, Z., Sun, Y., Fu, P., Li, J., Gao, J., and Wei, Y.: Modeling of aerosol property evolution during winter haze episodes over a megacity cluster in northern China: roles of regional transport and heterogeneous reactions of $\mathrm{SO}_{2}$, Atmos. Chem. Phys., 19, 9351-9370, https://doi.org/10.5194/acp19-9351-2019, 2019.

Ebert, M., Weigel, R., Kandler, K., Günther, G., Molleker, S., Grooß, J.-U., Vogel, B., Weinbruch, S., and Borrmann, S.: Chemical analysis of refractory stratospheric aerosol particles collected within the arctic vortex and inside polar stratospheric clouds, Atmos. Chem. Phys., 16, 8405-8421, https://doi.org/10.5194/acp-16-8405-2016, 2016.

Fan, X., Liu, J., Zhang, F., Chen, L., Collins, D., Xu, W., Jin, X., Ren, J., Wang, Y., Wu, H., Li, S., Sun, Y., and Li, Z.: Contrasting size-resolved hygroscopicity of fine particles derived by HTDMA and HR-ToF-AMS measurements between summer and winter in Beijing: the impacts of aerosol aging and local emissions, Atmos. Chem. Phys., 20, 915-929, https://doi.org/10.5194/acp-20-915-2020, 2020.

Feng, Y., Ramanathan, V., and Kotamarthi, V. R.: Brown carbon: a significant atmospheric absorber of solar radiation?, Atmos. Chem. Phys., 13, 8607-8621, https://doi.org/10.5194/acp13-8607-2013, 2013.

Hoffer, A., Tóth, A., Nyiró-Kósa, I., Pósfai, M., and Gelencsér, A.: Light absorption properties of laboratory-generated tar ball particles, Atmos. Chem. Phys., 16, 239-246, https://doi.org/10.5194/acp-16-239-2016, 2016.

IPCC: Climate change 2013: The Physical Science Basis, Contribution of Working Group I to the Fifth Assessment Report of the 
Intergovernmental Panel on Climate Change, Cambridge University Press, Cambridge, New York, USA, 2013.

Li, C., He, Q., Schade, J., Passig, J., Zimmermann, R., Meidan, D., Laskin, A., and Rudich, Y.: Dynamic changes in optical and chemical properties of tar ball aerosols by atmospheric photochemical aging, Atmos. Chem. Phys., 19, 139-163, https://doi.org/10.5194/acp-19-139-2019, 2019.

Li, H., Zhang, Q., Zhang, Q., Chen, C., Wang, L., Wei, Z., Zhou, S., Parworth, C., Zheng, B., Canonaco, F., Prévôt, A. S. H., Chen, P., Zhang, H., Wallington, T. J., and He, K.: Wintertime aerosol chemistry and haze evolution in an extremely polluted city of the North China Plain: significant contribution from coal and biomass combustion, Atmos. Chem. Phys., 17, 4751-4768, https://doi.org/10.5194/acp-17-4751-2017, 2017.

Li, J., Han, Z., Li, J., Liu, R., Wu, Y., Liang, L., and Zhang, R.: The formation and evolution of secondary organic aerosol during haze events in Beijing in wintertime, Sci. Total Environ., 703, 134937, https://doi.org/10.1016/j.scitotenv.2019.134937, 2020.

Li, M., Fan, X., Zhu, M., Zou, C., Song, J., Wei, S., Jia, W., and Peng, P. A.: Abundance and Light Absorption Properties of Brown Carbon Emitted from Residential Coal Combustion in China, Environ. Sci. Technol., 53, 595-603, https://doi.org/10.1021/acs.est.8b05630, 2019.

Li, W., Zhou, S., Wang, X., Xu, Z., Yuan, C., Yu, Y., Zhang, Q., and Wang, W.: Integrated evaluation of aerosols from regional brown hazes over northern China in winter: Concentrations, sources, transformation, and mixing states, J. Geophys. Res.-Atmos., 116, D09301, https://doi.org/10.1029/2010JD015099, 2011.

Li, W., Shao, L., Zhang, D., Ro, C.-U., Hu, M., Bi, X., Geng, H., Matsuki, A., Niu, H., and Chen, J.: A review of single aerosol particle studies in the atmosphere of East Asia: morphology, mixing state, source, and heterogeneous reactions, J. Clean. Prod., 112, 1330-1349, https://doi.org/10.1016/j.jclepro.2015.04.050, 2016a.

Li, W., Sun, J., Xu, L., Shi, Z., Riemer, N., Sun, Y., Fu, P., Zhang, J., Lin, Y., and Wang, X.: A conceptual framework for mixing structures in individual aerosol particles, J. Geophys. Res.-Atmos., 121, 13784-13798, https://doi.org/10.1002/2016JD025252, 2016 b.

Li, X., Yang, Y., Liu, S., Zhao, Q., Wang, G., and Wang, Y.: Light absorption properties of brown carbon $(\mathrm{BrC})$ in autumn and winter in Beijing: Composition, formation and contribution of nitrated aromatic compounds, Atmos. Environ., 223, 117289, https://doi.org/10.1016/j.atmosenv.2020.117289, 2020.

Lin, P., Aiona, P. K., Li, Y., Shiraiwa, M., Laskin, J., Nizkorodov, S. A., and Laskin, A.: Molecular Characterization of Brown Carbon in Biomass Burning Aerosol Particles, Environ. Sci. Technol., 50, 11815-11824, https://doi.org/10.1021/acs.est.6b03024, 2016.

Liu, D., Whitehead, J., Alfarra, M. R., Reyes-Villegas, E., Spracklen, D. V., Reddington, C. L., Kong, S., Williams, P. I., Ting, Y.-C., Haslett, S., Taylor, J. W., Flynn, M. J., Morgan, W. T., McFiggans, G., Coe, H., and Allan, J. D.: Black-carbon absorption enhancement in the atmosphere determined by particle mixing state, Nat. Geosci., 10, 184-188, https://doi.org/10.1038/ngeo2901, 2017.

Liu, J., Mauzerall, D. L., Chen, Q., Zhang, Q., Song, Y., Peng, W., Klimont, Z., Qiu, X., Zhang, S., Hu, M., Lin, W., Smith, K. R., and Zhu, T.: Air pollutant emissions from
Chinese households: A major and underappreciated ambient pollution source, P. Natl. Acad. Sci. USA, 113, 7756-7761, https://doi.org/10.1073/pnas.1604537113, 2016.

Liu, L., Kong, S., Zhang, Y., Wang, Y., Xu, L., Yan, Q., Lingaswamy, A. P., Shi, Z., Lv, S., Niu, H., Shao, L., Hu, M., Zhang, D., Chen, J., Zhang, X., and Li, W.: Morphology, composition, and mixing state of primary particles from combustion sources - crop residue, wood, and solid waste, Sci. Rep., 7, 5047, https://doi.org/10.1038/s41598-017-05357-2, 2017.

Liu, L., Zhang, J., Xu, L., Yuan, Q., Huang, D., Chen, J., Shi, Z., Sun, Y., Fu, P., Wang, Z., Zhang, D., and Li, W.: Cloud scavenging of anthropogenic refractory particles at a mountain site in North China, Atmos. Chem. Phys., 18, 14681-14693, https://doi.org/10.5194/acp-18-14681-2018, 2018.

Liu, P., Zhang, C., Xue, C., Mu, Y., Liu, J., Zhang, Y., Tian, D., Ye, C., Zhang, H., and Guan, J.: The contribution of residential coal combustion to atmospheric $\mathrm{PM}_{2.5}$ in northern China during winter, Atmos. Chem. Phys., 17, 11503-11520, https://doi.org/10.5194/acp-17-11503-2017, 2017.

Liu, P., Ye, C., Xue, C., Zhang, C., Mu, Y., and Sun, X.: Formation mechanisms of atmospheric nitrate and sulfate during the winter haze pollution periods in Beijing: gas-phase, heterogeneous and aqueous-phase chemistry, Atmos. Chem. Phys., 20, 4153-4165, https://doi.org/10.5194/acp-20-4153-2020, 2020.

Ma, Q., Wu, Y., Zhang, D., Wang, X., Xia, Y., Liu, X., Tian, P., Han, Z., Xia, X., Wang, Y., and Zhang, R.: Roles of regional transport and heterogeneous reactions in the $\mathrm{PM}_{2.5}$ increase during winter haze episodes in Beijing, Sci. Total Environ., 599, 246-253, https://doi.org/10.1016/j.scitotenv.2017.04.193, 2017.

Pósfai, M., Simonics, R., Li, J., Hobbs, P. V., and Buseck, P. R.: Individual aerosol particles from biomass burning in southern Africa: 1. Compositions and size distributions of carbonaceous particles, J. Geophys. Res.-Atmos., 108, 8483, https://doi.org/10.1029/2002JD002291, 2003.

Reid, J. P., Bertram, A. K., Topping, D. O., Laskin, A., Martin, S. T., Petters, M. D., Pope, F. D., and Rovelli, G.: The viscosity of atmospherically relevant organic particles, Nat. Commun., 9, 956, https://doi.org/10.1038/s41467-018-03027-z, 2018.

Riemer, N., Ault, A. P., West, M., Craig, R. L., and Curtis, J. H.: Aerosol Mixing State: Measurements, Modeling, and Impacts, Rev. Geophys., 57, 187-249, https://doi.org/10.1029/2018rg000615, 2019.

Seinfeld, J. H. and Pandis, S. N.: Atmospheric chemistry and physics: from air pollution to climate change, John Wiley \& Sons, New York, USA, 2006.

Shi, Z., Vu, T., Kotthaus, S., Harrison, R. M., Grimmond, S., Yue, S., Zhu, T., Lee, J., Han, Y., Demuzere, M., Dunmore, R. E., Ren, L., Liu, D., Wang, Y., Wild, O., Allan, J., Acton, W. J., Barlow, J., Barratt, B., Beddows, D., Bloss, W. J., Calzolai, G., Carruthers, D., Carslaw, D. C., Chan, Q., Chatzidiakou, L., Chen, Y., Crilley, L., Coe, H., Dai, T., Doherty, R., Duan, F., Fu, P., Ge, B., Ge, M., Guan, D., Hamilton, J. F., He, K., Heal, M., Heard, D., Hewitt, C. N., Hollaway, M., Hu, M., Ji, D., Jiang, X., Jones, R., Kalberer, M., Kelly, F. J., Kramer, L., Langford, B., Lin, C., Lewis, A. C., Li, J., Li, W., Liu, H., Liu, J., Loh, M., Lu, K., Lucarelli, F., Mann, G., McFiggans, G., Miller, M. R., Mills, G., Monk, P., Nemitz, E., O’Connor, F., Ouyang, B., Palmer, P. I., Percival, C., Popoola, O., Reeves, C., Rickard, A. R., Shao, L., Shi, G., Spracklen, D., Stevenson, D., Sun, Y., Sun, Z., Tao, S., 
Tong, S., Wang, Q., Wang, W., Wang, X., Wang, X., Wang, Z., Wei, L., Whalley, L., Wu, X., Wu, Z., Xie, P., Yang, F., Zhang, Q., Zhang, Y., Zhang, Y., and Zheng, M.: Introduction to the special issue "In-depth study of air pollution sources and processes within Beijing and its surrounding region (APHH-Beijing)", Atmos. Chem. Phys., 19, 7519-7546, https://doi.org/10.5194/acp19-7519-2019, 2019.

Song, J., Li, M., Jiang, B., Wei, S., Fan, X., and Peng, P. A.: Molecular Characterization of Water-Soluble Humic like Substances in Smoke Particles Emitted from Combustion of Biomass Materials and Coal Using Ultrahigh-Resolution Electrospray Ionization Fourier Transform Ion Cyclotron Resonance Mass Spectrometry, Environ. Sci. Technol., 52, 2575-2585, https://doi.org/10.1021/acs.est.7b06126, 2018.

Stein, A. F., Draxler, R. R., Rolph, G. D., Stunder, B. J. B., Cohen, M. D., and Ngan, F.: NOAA's HYSPLIT Atmospheric Transport and Dispersion Modeling System, B. Am. Meteorol. Soc., 96, 2059-2077, https://doi.org/10.1175/bams-d-14-00110.1, 2016.

Sun, J., Zhi, G., Hitzenberger, R., Chen, Y., Tian, C., Zhang, Y., Feng, Y., Cheng, M., Zhang, Y., Cai, J., Chen, F., Qiu, Y., Jiang, Z., Li, J., Zhang, G., and Mo, Y.: Emission factors and light absorption properties of brown carbon from household coal combustion in China, Atmos. Chem. Phys., 17, 4769-4780, https://doi.org/10.5194/acp-17-4769-2017, 2017.

Sun, Y., Jiang, Q., Wang, Z., Fu, P., Li, J., Yang, T., and Yin, Y.: Investigation of the sources and evolution processes of severe haze pollution in Beijing in January 2013, J. Geophys. Res.-Atmos., 119, 4380-4398, https://doi.org/10.1002/2014jd021641, 2014.

Sun, Y., Chen, C., Zhang, Y., Xu, W., Zhou, L., Cheng, X., Zheng, H., Ji, D., Li, J., Tang, X., Fu, P., and Wang, Z.: Rapid formation and evolution of an extreme haze episode in Northern China during winter 2015, Sci. Rep., 6, 27151, https://doi.org/10.1038/srep27151, 2016.

Toon, O. B. and Ackerman, T. P.: Algorithms for the calculation of scattering by stratified spheres, Appl. Optics, 20, 3657-3660, https://doi.org/10.1364/ao.20.003657, 1981.

Wang, B., Harder, T. H., Kelly, S. T., Piens, D. S., China, S., Kovarik, L., Keiluweit, M., Arey, B. W., Gilles, M. K., and Laskin, A.: Airborne soil organic particles generated by precipitation, Nat. Geosci., 9, 433-437, https://doi.org/10.1038/NGEO2705, 2016.

Wang, J., Nie, W., Cheng, Y., Shen, Y., Chi, X., Wang, J., Huang, X., Xie, Y., Sun, P., Xu, Z., Qi, X., Su, H., and Ding, A.: Light absorption of brown carbon in eastern China based on 3-year multiwavelength aerosol optical property observations and an improved absorption Ångström exponent segregation method, Atmos. Chem. Phys., 18, 9061-9074, https://doi.org/10.5194/acp18-9061-2018, 2018.

Wang, J., Li, J., Ye, J., Zhao, J., Wu, Y., Hu, J., Liu, D., Nie, D., Shen, F., Huang, X., Huang, D. D., Ji, D., Sun, X., Xu, W., Guo, J., Song, S., Qin, Y., Liu, P., Turner, J. R., Lee, H. C., Hwang, S., Liao, H., Martin, S. T., Zhang, Q., Chen, M., Sun, Y., Ge, X., and Jacob, D. J.: Fast sulfate formation from oxidation of $\mathrm{SO}_{2}$ by $\mathrm{NO}_{2}$ and $\mathrm{HONO}$ observed in Beijing haze, Nat. Commun., 11, 2844, https://doi.org/10.1038/s41467-020-16683-x, 2020.

Wang, X., Heald, C. L., Ridley, D. A., Schwarz, J. P., Spackman, J. R., Perring, A. E., Coe, H., Liu, D., and Clarke, A. D.: Exploiting simultaneous observational constraints on mass and absorption to estimate the global direct radiative forcing of black car- bon and brown carbon, Atmos. Chem. Phys., 14, 10989-11010, https://doi.org/10.5194/acp-14-10989-2014, 2014.

Wang, Y., Liu, F., He, C., Bi, L., Cheng, T., Wang, Z., Zhang, H., Zhang, X., Shi, Z., and Li, W.: Fractal Dimensions and Mixing Structures of Soot Particles during Atmospheric Processing, Environ. Sci. Tech. Let., 4, 487-493, https://doi.org/10.1021/acs.estlett.7b00418, 2017.

West, J. J., Cohen, A., Dentener, F., Brunekreef, B., Zhu, T., Armstrong, B., Bell, M. L., Brauer, M., Carmichael, G., and Costa, D. L.: What We Breathe Impacts Our Health: Improving Understanding of the Link between Air Pollution and Health, Environ. Sci. Technol., 50, 4895-4904, https://doi.org/10.1021/acs.est.5b03827, 2016.

Wu, C., Wu, D., and Yu, J. Z.: Quantifying black carbon light absorption enhancement with a novel statistical approach, Atmos. Chem. Phys., 18, 289-309, https://doi.org/10.5194/acp-18-2892018, 2018.

Xie, C., Xu, W., Wang, J., Wang, Q., Liu, D., Tang, G., Chen, P., Du, W., Zhao, J., Zhang, Y., Zhou, W., Han, T., Bian, Q., Li, J., Fu, P., Wang, Z., Ge, X., Allan, J., Coe, H., and Sun, Y.: Vertical characterization of aerosol optical properties and brown carbon in winter in urban Beijing, China, Atmos. Chem. Phys., 19, 165179, https://doi.org/10.5194/acp-19-165-2019, 2019.

Xing, L., Fu, T.-M., Cao, J. J., Lee, S. C., Wang, G. H., Ho, K. F., Cheng, M.-C., You, C.-F., and Wang, T. J.: Seasonal and spatial variability of the OM/OC mass ratios and high regional correlation between oxalic acid and zinc in Chinese urban organic aerosols, Atmos. Chem. Phys., 13, 4307-4318, https://doi.org/10.5194/acp-13-4307-2013, 2013.

Xu, J., Srivastava, D., Wu, X., Hou, S., Vu, T. V., Liu, D., Sun, Y., Vlachou, A., Moschos, V., Salazar, G., Szidat, S., Prevot, A., Fu, P., Harrison, R. M., and Shi, Z.: An evaluation of source apportionment of fine $\mathrm{OC}$ and $\mathrm{PM}_{2.5}$ by multiple methods: APHH-Beijing campaigns as a case study, Faraday Discuss., https://doi.org/10.1039/D0FD00095G, online first, 2021.

Xu, W., Sun, Y., Wang, Q., Zhao, J., Wang, J., Ge, X., Xie, C., Zhou, W., Du, W., Li, J., Fu, P., Wang, Z., Worsnop, D. R., and Coe, H.: Changes in Aerosol Chemistry From 2014 to 2016 in Winter in Beijing: Insights From High-Resolution Aerosol Mass Spectrometry, J. Geophys. Res.-Atmos., 124, 1132-1147, https://doi.org/10.1029/2018jd029245, 2019.

Yan, C., Zheng, M., Bosch, C., Andersson, A., Desyaterik, Y., Sullivan, A. P., Collett, J. L., Zhao, B., Wang, S., He, K., and Gustafsson, Ö.: Important fossil source contribution to brown carbon in Beijing during winter, Sci. Rep., 7, 43182, https://doi.org/10.1038/srep43182, 2017.

Yu, H., Li, W., Zhang, Y., Tunved, P., Dall'Osto, M., Shen, X., Sun, J., Zhang, X., Zhang, J., and Shi, Z.: Organic coating on sulfate and soot particles during late summer in the Svalbard Archipelago, Atmos. Chem. Phys., 19, 10433-10446, https://doi.org/10.5194/acp-19-10433-2019, 2019.

Zhang, J., Liu, L., Wang, Y., Ren, Y., Wang, X., Shi, Z., Zhang, D., Che, H., Zhao, H., Liu, Y., Niu, H., Chen, J., Zhang, X., Lingaswamy, A. P., Wang, Z., and Li, W.: Chemical composition, source, and process of urban aerosols during winter haze formation in Northeast China, Environ. Pollut., 231, 357-366, https://doi.org/10.1016/j.envpol.2017.07.102, 2017.

Zhang, J., Liu, L., Xu, L., Lin, Q., Zhao, H., Wang, Z., Guo, S., Hu, M., Liu, D., Shi, Z., Huang, D., and Li, W.: Explor- 
ing wintertime regional haze in northeast China: role of coal and biomass burning, Atmos. Chem. Phys., 20, 5355-5372, https://doi.org/10.5194/acp-20-5355-2020, 2020.

Zhang, Q. and Geng, G.: Impact of clean air action on $\mathrm{PM}_{2.5}$ pollution in China, Sci. China Earth Sci., 62, 1845-1846, https://doi.org/10.1007/s11430-019-9531-4, 2019.

Zhang, Y., Yuan, Q., Huang, D., Kong, S., Zhang, J., Wang, X., Lu, C., Shi, Z., Zhang, X., Sun, Y., Wang, Z., Shao, L., Zhu, J., and Li, W.: Direct observations of fine primary particles from residential coal burning: insights into their morphology, composition, and hygroscopicity, J. Geophys. Res.-Atmos., 123, 1296412979, https://doi.org/10.1029/2018JD028988, 2018.

Zheng, G. J., Duan, F. K., Su, H., Ma, Y. L., Cheng, Y., Zheng, B., Zhang, Q., Huang, T., Kimoto, T., Chang, D., Pöschl, U., Cheng, Y. F., and He, K. B.: Exploring the severe winter haze in Beijing: the impact of synoptic weather, regional transport and heterogeneous reactions, Atmos. Chem. Phys., 15, 2969-2983, https://doi.org/10.5194/acp-15-2969-2015, 2015.
Zhong, J., Zhang, X., Wang, Y., Wang, J., Shen, X., Zhang, H., Wang, T., Xie, Z., Liu, C., Zhang, H., Zhao, T., Sun, J., Fan, S., Gao, Z., Li, Y., and Wang, L.: The two-way feedback mechanism between unfavorable meteorological conditions and cumulative aerosol pollution in various haze regions of China, Atmos. Chem. Phys., 19, 3287-3306, https://doi.org/10.5194/acp19-3287-2019, 2019. 